\title{
Effect of Feeding Commercial Chicken Salad with Dressing on Body Weight and Plasma Lipid Profile of Albino Rats
}

\author{
Aladesuru Oluwaseun Omolabake ${ }^{1}$, Bisuga N.A. ${ }^{2}$, Ketiku Adegboyega O. ${ }^{3}$ \\ ${ }^{1,2,3}$ (Department of Biochemistry/Olabisi Onabanjo University, Ikenne Campus, Nigeria)
}

\begin{abstract}
Body weight, lipid profile, atherogenic index and coronary risk index were determined in rats fed commercial chicken salad with dressing. Twenty four weaning albino rats were divided into three groups of eight animals, baseline, rat chow (control) and chicken salad with dressing and fed respective diets, for five weeks. Body weights, serum cholesterol, serum triglycerides, HDL cholesterol and LDL cholesterol were determined using standard methods. Atherogenic and coronary risk indices were also calculated. Body weights and lipids profiles of animals on regular rat chow and chicken salad groups increased with age. Weight gain in rats fed chicken salad with dressing increased significantly $(P<0.05)$ and had higher serum cholesterol, triglyceride, HDL cholesterol and LDL cholesterol values compared with the rat chow group. The observed increases in parameters evaluated might be due to the chicken component and salad dressing comprising of both mayonnaise and salad cream. Despite the observed absolute increase in the lipid profile values of the chicken salad with dressing group, the coronary risk index, atherogenic index, HDL cholesterol/total cholesterol ratio and triglyceride/HDL cholesterol ratios were within normal range and not significantly $(P>0.05)$ different from the corresponding values for the rat chow fed group. It is however desirable that a similar study be carried out with human subjects.
\end{abstract}

Keywords: Atherogenic Index, Body Weight, Chicken Salad, Coronary Risk Index, Salad Dressing, Lipid Profile.

\section{Introduction}

The literature is replete with research findings associating high plasma cholesterol levels with increased risk of coronary heart disease. Many successful attempts have been made to reduce plasma cholesterol levels to those compatible with maintenance of good health through the use of drugs and dietary management. Hepner $e t$ al in 1979 (1) reported a reduction in plasma cholesterol levels through consumption of vegetables such as carrots, lettuce, cucumber, cabbage and potatoes. Lettuce, maize and beans have been found to reduce on consumption, total plasma cholesterol values (2).

Vegetarians have been shown to have reduced risk of cardiovascular diseases and coronary heart diseases (3). Salad is regarded as a light meal that consists of mixed vegetables, which can be consumed with or without dressing. Fish, meat or cheese may be added to the salad. Consumers of fruits and vegetables have also been shown to have lower morbidity (4) and mortality (5) rates from chronic degenerative diseases than their non-vegetarian counterparts. The reduced morbidity and mortality have been attributed to lower total serum cholesterol, LDL - cholesterol and high values of HDL cholesterol depending on the type of fruits and vegetables (6).

In Nigeria, chicken salad with dressing is a popular meal sold in some commercial food outlets and its consumption has no religious or cultural barriers. The components include vegetables chicken meat and salad dressing. Chicken meat is an important source of lipid with 35\% saturated fatty acids (7) and saturated fatty acids have been linked to increased plasma cholesterol level (8).

The aim of this study was to establish the effect of the 'consumption of chicken salad with dressing on body weight, lipid profile and the corresponding indices of risks of cardiovascular diseases in rats.

\section{Materials And Methods}

Chicken salad with dressing was purchased at a commercial food outlet in Lagos. The rat chow was obtained from Ladokun Feeds Limited. The twenty-four weanling albino rats were purchased from the Animal House of the University of Ibadan. The chicken salad samples were air-oven dried at low temperature $\left(60^{\circ} \mathrm{C}\right)$ and milled for the rat feeding trial. The twenty-four weaning albino rats were randomly allocated to three groups of eight animals after acclimatization. Group 1 served as the baseline, Group 2 was given rat chow and Group 3 was given chicken salad with dressing. The rats were allowed free access to water and feed ad-libitum (rat chow and chicken salad with dressing respectively). Blood samples obtained from the baseline rats and from the experimental rats at the end of the feeding period were used for the estimation of total cholesterol, HDL cholesterol, LDL cholesterol and triglyceride using standard methods and using cromatest kits supplied by Randox laboratory Limited. Atherogenic and coronary risk indices as well as triglyceride/HDL ratios were 
calculated. Body weight changes of the experimental rats were measured. Standard Package for Social Sciences (SPSS) version 12 was applied for the statistical analysis using the Duncan approach.

\section{Results and Discussion}

\subsection{Results}

Table 1 shows the food components of chicken salad with dressing as listed on the nutrition label.

Table 1:Food combonents of chicken salad with dressing

- Cabbage

- Cucumber

- Carrot

- Lettuce

- Kidney beans

- Tomatoes

- Chicken meat
- Boiled Egg

- Green peas

- Mayonnaise

- Salad cream

- Ketchup

- Macaroni

- Potatoes

The nutrition label did not indicate the relative proportions of the ingredients listed above. The chicken salad with dressing is a mixture of animal and plant foods which should have high nutritional value.

Table 2 shows the weight changes of the rats fed rat chow and chicken salad with dressing.

Table 2: Body weight changes of rats fed experimental diets

\begin{tabular}{|l|l|l|}
\hline & Rat chow & Chicken salad with dressing \\
\hline Initial Body weight $(\mathrm{g})$ & $5 \mathrm{G} .6 \pm 2.0$ & $58.9+1.7$ \\
\hline Final Body Weight $(\mathrm{g})$ & $124.9 \pm 3.9$ & $164.0+2.8$ \\
\hline Weight Gain $(\mathrm{g})$ & $68.3 \pm 1.9$ & $105.1 \pm 1.1$ \\
\hline
\end{tabular}

NB: Values are means \pm standard error of means

The rats fed regular commercial feed (rat chow) and chicken salad gained body weight. However, the rats fed chicken salad with dressing gained significantly $(\mathrm{P}<0.05)$ more weight than those on rat chow. This could be attributed to the high nutritional quality of the food components of chicken salad with dressing such as the egg, chicken and legume components.

Table 3 shows the lipid profile of the baseline rats, and those fed with rat chow and chicken salad with dressing.

Table 3: Lipid profile of baseline rats, rat chow and chicken salad with dressing groups.

\begin{tabular}{|l|l|l|l|}
\hline \multicolumn{1}{|c|}{ Lipid profiles in $(\mathbf{m g} / \mathbf{d l})$} & \multicolumn{1}{|c|}{ Baseline } & \multicolumn{1}{c|}{ Rat chow } & \multicolumn{1}{c|}{$\begin{array}{c}\text { Chicken salad with } \\
\text { dressing }\end{array}$} \\
\hline Total cholesterol & $81.0 \pm 1.8^{\mathrm{a}}$ & $112.4 \pm 1.5^{\mathrm{b}}$ & $171.6 \pm 1.8^{\mathrm{c}}$ \\
\hline Triglyceride & $61.4 \pm 1.7^{\mathrm{a}}$ & $87.6 \pm 1.7^{\mathrm{b}}$ & $141.3 \pm 1.4^{\mathrm{c}}$ \\
\hline HDL cholesterol & $34.7 \pm 0.9^{\mathrm{a}}$ & $44.8 \pm 0.9^{\mathrm{b}}$ & $68.2 \pm 1.3^{\mathrm{c}}$ \\
\hline LDL cholesterol & $34.0 \pm 0.6^{\mathrm{a}}$ & $50.1 \pm 1.7^{\mathrm{b}}$ & $75.1 \pm 0.4^{\mathrm{c}}$ \\
\hline
\end{tabular}

NB: Figures with different superscripts within the rows are significantly $(\mathrm{P}<0.05)$ different.

$\mathrm{NB}$ : values are means \pm standard error of means

The values of total cholesterol, HDL cholesterol, LDL cholesterol and triglycerides increased with the age of the rats from the beginning to the end of the experimental period for both rat chow group and chicken salad with dressing group. However, Group 3 animals on chicken salad with dressing had significantly ( $\mathrm{P}$ « 0.05 ) higher values of the cholesterol types and triglycerides than the rat chow group. This might be attributed to the inclusion of chicken meat, egg and mayonnaise in the chicken salad with dressing while casein was the only animal protein in the rat chow. 
Table 4 shows the atherogenic index, coronary risk index and triglyceride/HDL ratio of the three groups.

Table 4: Atherogenic and Coronary risk indices and triglyceride/HDL ratio of rats in baseline, rat chow and chicken salad with dressing groups.

\begin{tabular}{|c|c|c|c|}
\hline & Baseline & Rat Chow & $\begin{array}{l}\text { Chicken salad } \\
\text { with dressing }\end{array}$ \\
\hline $\begin{array}{l}\text { Atherogenic Index }=\underline{\text { LDL cholesterol }} \\
\text { HDL cholesterol } \\
\text { (9) }\end{array}$ & $0.98 \pm 0.1$ & $1.11 \pm 0.2$ & $1.10 \pm 0.1$ \\
\hline $\begin{array}{l}\text { Coronary Risk Index }=\frac{\text { Total cholesterol }}{\text { HDL cholesterol }} \\
(10)\end{array}$ & $2.33 \pm 0.1$ & $2.48 \pm 0.2$ & $2.51 \pm 0.1$ \\
\hline $\begin{array}{l}\text { Trig/HDL ratio }=\frac{\text { Triglyceride }}{\text { HDL cholesterol }} \\
(11,12)\end{array}$ & 1.77 & 1.93 & 2.07 \\
\hline
\end{tabular}

The indices in Table 4 are indicators or predictors of risks of cardiovascular diseases. Coronary risk index value of between 2 and 3 is indicative of low risk of cardiovascular diseases. For the rat chow and chicken salad with dressing the value is 2.5 which is considered desirable. For triglyceride/HDL ratio which is one of the most potent predictors of heart Diseases, a ratio of 2 or less is considered ideal. The corresponding figures for rat chow and chicken salad with dressing group are 1.93 and 2.07 which are still considered desirable.

\subsection{Discussion}

Comparison between the data collected from the rat chow group and chicken salad group on body weight, and lipid profile before and after the period of study indicated that body weight and lipid profile increases with age. Consumption of chicken salad with dressing promoted growth during the period of study more than the rat chow which could be due to the presence of more energy content in the chicken salad with dressing $(13,14)$. The rats fed chicken salad with dressing had higher lipid profile i.e. serum cholesterol, triglyceride, HDL cholesterol and LDL cholesterol than the rat chow group. These observed increases could be due to the fact that most of the components of the chicken salad with dressing e.g. chicken, mayonnaise, egg and salad cream naturally increases lipid profile. Diets very low in fat e.g. vegetables have been shown to significantly reduce total serum cholesterol but when fat was added to these diets, the serum cholesterol rose rapidly. Using data from the 1985 continuing survey of food intake by individuals, Krebs Smith et al., (15) identified salad dressing as the major source of fat in women's diet. Over the past 10years, there has been steady growth in demand for low fat salad dressings and mayonnaise (16). Although the lipid profile of the rats in the chicken salad group was higher, it still falls within the desirable lipid levels reported by NECP $2001(17,18)$ and using the data from the atherogenic index, coronary risk index, triglyceride/HDL cholesterol ratio and HDL cholesterol/cholesterol ratio which are determinants or markers of cardiovascular risk factors which indicates that the diet is still desirable which supports a previous study that says a diet rich in salad intake (like consumption of salads, vegetables and salad dressing) may improve health by assuring needs are met. The observed results for the atherogenic index and others also indicates that the diet, although rich in cholesterol might not predispose the subjected to atherogenic and coronary heart diseases and this supports the findings that suggests that the vegetables in salad are essentially fat free but rich in carotenoids which need fat to be absorbed. By choosing reduced fat or fat free salad dressings, consumer could preferentially compromise their exposure to the putative bioactivity of these carotenoids in preventing heart disease $(19,20)$.

\section{Conclusion}

This study has demonstrated that both rat chow and chicken salad with dressing supported body weight gain in rats and increased lipid profile value. But they may not predispose to risk of heart diseases because of their desirable coronary risk index values and triglyceride/HDL-cholesterol ratios. It is however, desirable to carry out a similar study with humans.

\section{References}

[1] G Hepner, S Fried, S St Jeor: Hypocholesterolemic effect of yogurt and milk. Am J ClinNutr 1979; 19-24.

[2] H.L. Rui: Fruit and vegetable intake and risk of cardiovascular disease Ann Intern Med 2001; 134:1106-1114

[3] M.D. Walter C. Willett (Author), P.J. Skerrett (Contributor). Eat, Drink, and Be Healthy: The Harvard Medical School Guide to Healthy Eating.Apr 8, 2004

[4] S.F. Knutsen: Lifestyles and the use of health service Am-J ClinNutr. 59 (suppl) 1994; 1715-11755.

[5] A. Keys et al., Dietary habits and mortality in 11,000 vegetarian and health conscious people: results of a $17 y e a r$ follow up BMJ 1996; 313:775-779. 
[6] C.L. Melbyet al., Blood pressure and blood lipids among vegetable semivegetation and non vegetarian African Americans. Am L. Clin.Nutr 1994; 59:103-109.

[7] A.A. Paul, D.A.T. Southgate: McCance and Widdowsons' The Composition of Foods 4th edition London HMSO 1978.

[8] A. Keys: Seven countries, a multivariate analysis on death and coronary heart disease, Harvard University Press Cambridge M.A. $1980 ; 132-133$.

[9] R.D. Abbot, P.W.F. Wilson, W.B. Karvel and W.P. Castelli: High density lipoprotein cholesterol and total cholesterol screening myocardial infarction. The Framingham Study.Atherosclerosis 1998; 8: 207-211.

[10] S.A. Alladi, A. Khada, M. Shanmugan: Induction of hypercholesterolemia by simple soil protein and acetate generating amino acid.Nutr. Rep. Int. 1989; 40:893-894

[11] V. Hanak, J. Muñoz, J. Teague, A. Stanley, V. Bittner: Accuracy of the triglyceride to high-density lipoprotein cholesterol ratio for prediction of the low-density lipoprotein phenotype B. Am J Cardiol 2004; 94: 219-222

[12] C. Maruyama, K. Imamura, T. Teramoto: Assessment of LDL particle size by triglyceride/HDL-cholesterol ratio in non-diabetic, healthy subjects without prominent hyperlipidemia. J AtherosclerThromb 2003; 10: 186-191, 2003

[13] R. Passmore, M.A. Eastwood, L.S.P. Davidson: Hyperlipidemia Pg. 352-357, 1986. (Human Nutrition and diabetics, Eighth edition, ELBS/ Churchil Living Stone).

[14] R. Passmoreet al., (Human Nutrition and dietetics. Field Edition ELBS 1 church Livingstone) 1986.

[15] S.M. Kreb, F.J. Cronin, D.B.A. Haytowitz, D.A. Cook: Food sources of energy, macronutrients, cholesterol and fiber in diets of women. J Am diet Assoc; 1992:168-74.

[16] D.K. Sandrou, I.S. Arvanitoyannis: Low fat/calorie foods: current state and perspective. Crit. Rev Food sci. Nutr.2000; 40:427-47.

[17] National Cholesterol Education program. Report of the expert panel on population strategies for blood cholesterol reduction: (Executive summary 3rd Inter Med.) 1991; 151:1071-1074.

[18] Executive summary of the third report of the National Cholesterol Education Program (NCEP). Expert panel on detection, evaluation and treatment of high blood cholesterol in adults. (Adult treatment panel III) JAMA, 2001 May 16; 285(19): $2486-97$.

[19] A. D'odorico, D. Martins, S. Kiechl S: High plasma levels of a and p carotene are associated with a lower risk of atherosclerosis: result from the Bruneck study. Artherosclerosis 2000; 153:231-9

[20] CL Perry et al: Changing fruits and vegetable consumption among children. 1996 March 13, 275(10): 768-776.

[21] P.A. Akinyanju, R.V. Kureshi, A.L. Salter, Yudkin: American Journal of Clinical Nutrition, Vol. 81, No. 2,380-387, February 2005.

[22] L.J. Berlin: Vegetarian and other complex diets, fats fibre and hypertension. Am J. Clin Nuts 59, 1994:1130-1135.

[23] A. Bonanome, S. M Grundy: Effect of dietary stearic acid on plasma cholesterol and lipoprotein levels. Nutr. Engl. JP Med. 1985; 3181:1244-1248.

[24] S.P. Datta, J.R. Ottawa; Techniques pp 436-463; (Biochemistry Concise Medical Textbooks, Billere Tindal) 1976.

[25] T.R. Dawker: Eggs serum cholesterol and coronary heart disease Am. J. Clin Nuts 1972; 36:617-625.

[26] J.T. Duyer: Health aspects of vegetarian diet. Am. J. ClinNutr. 1988; 48:712-738.Effect of an atherogenic diet containing starch or sucrose on blood lipids of young men.Nature 218: 975-977.

[27] European Study Group, Atherosclerosis Society; strategies for prevention for coronary heart disease. A policy statement of the European atherosclerosis society, 1957.European Heart Journal.

[28] S.M. Grundy: Comparison of non-saturated fatty acids and carbohydrates for lowering plasma cholesterol. N. Engl. J. Med 1986; 314:745-748.

[29] S.M. Grundy, A.M. Denke: Dietary influence on seven lipids and lipoproteins. Journal of Lipid Research 1990; 31:25-33.

[30] A.R. Ness: Fruit and vegetables and cardiovascular disease: Int. J Epidemol 1997; 26:1-13.

[31] US department of agriculture, US department of health and human services. Nutrition and your health; Dietary guidelines for Americans 20th June, 2001. 